University of Nebraska - Lincoln

DigitalCommons@University of Nebraska - Lincoln

Faculty Publications, Department of Child, Youth, and Family Studies

Child, Youth, and Family Studies, Department of

2020

Does context matter? A multilevel analysis of neighborhood

disadvantage and children's sleep health

Carlyn Graham

Eric N. Reither

Gabriele Ciciurkaite

Dipti Dev

Jamison Fargo

Follow this and additional works at: https://digitalcommons.unl.edu/famconfacpub

Part of the Developmental Psychology Commons, Family, Life Course, and Society Commons, Other Psychology Commons, and the Other Sociology Commons

This Article is brought to you for free and open access by the Child, Youth, and Family Studies, Department of at DigitalCommons@University of Nebraska - Lincoln. It has been accepted for inclusion in Faculty Publications, Department of Child, Youth, and Family Studies by an authorized administrator of DigitalCommons@University of Nebraska - Lincoln. 


\title{
Does context matter? A multilevel analysis of neighborhood disadvantage and children's sleep health
}

\author{
Carlyn Graham, ${ }^{1}$ Eric N. Reither, ${ }^{2,3}$ Gabriele Ciciurkaite, ${ }^{3}$ \\ Dipti A. Dev, 4 \& Jamison Fargo ${ }^{3}$ \\ 1 Pennsylvania State University, Pennsylvania \\ 2 Department of Sociology, Social Work and Anthropology, \\ Utah State University, Logan, Utah \\ 3 Utah State University, Logan, Utah \\ 4 University of Nebraska-Lincoln, Lincoln, Nebraska \\ Corresponding author - Eric N. Reither, Department of Sociology, Social Work and Anthropology, \\ Utah State University, o730 Old Main Hill, Logan, UT 84322-0730. Email eric.reither@usu.edu
}

\begin{abstract}
Objectives: To determine how demographic, socioeconomic, and neighborhood characteristics are associated with bedtimes among US kindergarteners.

Design: Parents reported bedtimes of their children as well as personal, household, and residential characteristics via interviews in the Early Childhood Longitudinal Study-Kindergarten (ECLS-K) Class of 1998-1999. The ECLS-K links individual households to US Census tracts.

Setting: A random selection of 1,280 schools and surrounding communities in the US.

Participants: A random selection of 16,936 kindergarteners and their parents.

Measurements: The 2 outcomes were regular and latest weekday bedtimes of kindergarteners. Through a series of nested multilevel regression models, these outcomes were regressed on individual and neighborhood-level variables,
\end{abstract}

Published in Sleep Health (2020), 9pp

DOI: 10.1016/j.sleh.2020.05.002

Copyright (C) 2020 National Sleep Foundation. Published by Elsevier Inc. Used by permission. 
including race/ethnicity, sex, family type, household income, mother's educational attainment, neighborhood disorder, and several additional neighborhood characteristics.

Results: Models showed significant $(P<.05)$ bedtime disparities by race/ethnicity, sex, family income, and mother's educational attainment. Additionally, models tended to indicate that kindergarteners from disadvantaged neighborhoods experienced later bedtimes than children from more advantaged areas. Neighborhood characteristics accounted for a portion of racial/ethnic differences, suggesting that bedtime disparities are partly rooted in disparate environmental conditions.

Conclusions: Reducing disparities in childhood sleep may require programs that target not only children and their parents, but also the communities in which they reside.

Keywords: United states, Sleep, Bedtime, Children, Neighborhoods, ECLS-K, Census tracts, multilevel models

\section{Introduction}

Approximately $40 \%$ of childhood is spent sleeping, as adequate sleep is vital to physical, cognitive, and emotional development. ${ }^{1} \mathrm{~A}$ consensus statement from the American Academy of Sleep Medicine indicates that infants require between 12 and 16 hours of sleep per day. ${ }^{2}$ This figure declines steadily as children age, reaching 8-10 hours for adolescents aged 13-18. In addition to sleep duration, factors such as sleep latency (i.e., the time required to fall asleep) and the frequency of night-time awakenings affect sleep adequacy during childhood. ${ }^{3}$ Consequences of inadequate sleep in childhood include diminished physical, cognitive, and emotional health; these associations are especially pronounced among young children..$^{-6}$ In addition to its intrinsic importance, a healthy childhood is essential because it establishes health trajectories that reverberate across the life course. ${ }^{7}$

During early childhood, kindergarten is a critical and understudied period of sleep transition. ${ }^{8,9}$ One recent study found that the transition to kindergarten reduces weekday nap duration and alters the timing of nocturnal sleep, leading to an average decline of 38 minutes in total sleep duration on each weekday. ${ }^{9}$ For parents, one of the main challenges kindergarten poses is the adoption of new bedtime routines, particularly if the child did not attend preschool. Bedtime (i.e., when "lights out" tends to occur) is important, as it is 
strongly associated with sleep onset and sleep duration among kindergarteners. ${ }^{8}$ Moreover, consistent bedtimes in early childhood improve sleep quality and related markers of wellbeing, such as cognitive function. ${ }^{10}$ Therefore, it is important to consider both the timing and regularity of bedtimes during the kindergarten transition, as prior research has linked these factors to children's sleep and overall wellbeing.

Demographic factors and socioeconomic conditions affect bedtimes and other indicators of sleep adequacy among children. ${ }^{11-16}$ These findings are consistent with theories in social epidemiology that highlight disadvantaged social conditions as fundamental causes of health outcomes and health inequalities. ${ }^{17}$ For instance, nonHispanic black and Hispanic children tend to have later and less consistent bedtimes, and receive less night-time sleep than non-Hispanic white children. ${ }^{13-15}$ Similarly, children from households with low socioeconomic status tend to have more sleep problems, later bedtimes, and earlier wake times than children from more advantaged households. ${ }^{11,13,14}$

In addition to the demographic and socioeconomic characteristics of children and their parents, some studies suggest that disadvantaged neighborhoods contribute to sleep deficiencies. ${ }^{18,19}$ For example, a longitudinal study in California found that neighborhoods long entrenched in poverty have detrimental effects on children's sleep quality. ${ }^{20}$ Additionally, a nationally-representative study of children aged 617 -the only nationally representative study to our knowledge of neighborhood conditions and children's sleep-found that children from deteriorating and unsafe neighborhoods were significantly less likely than children from stable neighborhoods to receive adequate sleep.$^{18}$ However, no prior study has used nationally representative data to examine the simultaneous influence of demographic, socioeconomic, and neighborhood characteristics on sleep traits specific to kindergarten-aged children (about 5 years of age, on average). Our investigation addresses this gap in the literature by exploring the influence of individual and neighborhood-level characteristics on the regular and latest bedtimes of kindergarteners, using data from the Early Childhood Longitudinal Study-Kindergarten (ECLS-K) Class of 1998-1999. 


\section{Background}

In the following sections, we review extant literature on the demographic, socioeconomic, and neighborhood determinants of children's sleep. Through this process, we generate several research hypotheses that provide the framework for our methodological approach.

\section{Demographic contributors to childhood sleep inadequacies}

Demographic characteristics are associated with sleep disparities in childhood. Several studies have found associations between race/ ethnicity and sleep problems among children. ${ }^{12-14,1}$ When socioeconomic status is held constant across racial and ethnic groups, non-Hispanic black and Hispanic children tend to have later bedtimes, less consistent bedtimes, nap more during the day, and sleep less during the night than their non-Hispanic white counterparts. ${ }^{12-15}$ However, non-Hispanic white mothers are more likely than Hispanic or non-Hispanic black mothers to report concerns about their children's sleep. ${ }^{16}$

In addition to race/ethnicity, studies have explored whether a child's sex and family structure may affect sleep outcomes. Whereas one large, nationally representative study failed to detect significant gender differences in sleep adequacy, ${ }^{18}$ other studies have found that male children and adolescents go to bed later and receive less nighttime sleep than female children and adolescents. ${ }^{21,22}$ Compared to children in two-parent households, children living with a single mother tended to receive fewer days of adequate sleep during 5and 7-day reporting periods. ${ }^{18}$ Children living in single-mother households are also less likely to use regular bedtime routines than children in two-parent households. ${ }^{15}$

Based on these observations, we propose the following hypotheses about demographic contributors to regular and latest bedtimes among kindergarten-aged children in the ECLS-K:

1a Racial and ethnic minority children tend to have later bedtimes than non-Hispanic white children.

1b Male children tend to have later bedtimes than female children. 
1c Children in single-parent households tend to have later bedtimes than children in two-parent households.

\section{Socioeconomic contributors to childhood sleep inadequacies}

Using a variety of measures for socioeconomic status, a handful of studies suggest that low socioeconomic status has an adverse impact on children's sleep duration and sleep quality. ${ }^{11,13,14}$ Children with parents who make less than the average US household income, live below the poverty line, or experience self-perceived economic hardship have shorter nocturnal sleep duration and poorer sleep quality than children with wealthier parents. ${ }^{13,14}$ The educational attainment of parents is also positively associated with children's sleep quantity and quality, particularly with respect to the educational attainment of mothers. ${ }^{13}$

Given these research findings, we propose the following hypotheses regarding socioeconomic contributors to regular and latest bedtimes among children in the ECLS-K:

H1a Children in high-income households tend to have earlier bedtimes than children in households with less income.

$\mathrm{H} 1 \mathrm{~b}$ Children of mothers with a high level of educational attainment tend to have earlier bedtimes than children of less educated mothers.

\section{Neighborhood contributors to childhood sleep inadequacies}

In addition to demographic and socioeconomic contributors, environmental conditions such as neighborhood disorder can influence sleep quality and quantity among children, adolescents, and adults. Disorderly neighborhoods are characterized by social dysfunction and infrastructural disrepair, such as high rates of crime and abandoned buildings. ${ }^{23}$ Neighborhood disorder contributes to psychological distress and negative self-rated health, which is partly mediated by sleep quality. ${ }^{24,25}$ Furthermore, low levels of neighborhood socioeconomic status and social capital are associated with shorter sleep duration and more daytime sleepiness. ${ }^{26,27}$ Even after controlling for individual-level characteristics, residents of low and middle socioeconomic status neighborhoods tend to have shorter sleep duration than residents of high socioeconomic status neighborhoods. ${ }^{28}$ 
With specific regard to children and adolescents, living in disadvantaged neighborhoods contributes to shorter sleep duration and sleep disorders such as obstructive sleep apnea. ${ }^{18,19}$ In the largest study to date on this issue, Singh and Kenney ${ }^{18}$ used data from the National Survey of Children's Health to examine associations between neighborhood conditions and sleep adequacy. This investigation found that children living in neighborhoods with few health promoting amenities and unfavorable social and infrastructural conditions were less likely to receive adequate sleep than children from more advantaged neighborhoods.

Smaller-scale studies have also detected associations between neighborhood characteristics and sleep among children and adolescents. Troxel et $\mathrm{al}^{29}$ examined neighborhood disadvantage and adolescents' sleep in a racially and ethnically diverse sample of adolescents in Southern California. These authors found that adolescents from socially cohesive neighborhoods reported fewer instances of sleep trouble than adolescents from neighborhoods with low levels of social cohesion. Using data from the 2008 Boston Youth Survey, Pabayo et al ${ }^{30}$ also found that high and moderate levels of social fragmentation (i.e., fractured social bonds that reduce self-regulation and promote unstable communities) within neighborhoods contributed to inadequate sleep among high school students. Additionally, in a cross-sectional analysis of data from the Cleveland Children's Sleep and Health Study, Spilsbury et $\mathrm{al}^{19}$ detected a significant association between neighborhood socioeconomic disadvantage and obstructive sleep apnea among children aged 811.

Extrapolating from these studies, we propose the following hypotheses regarding neighborhood conditions and both regular and latest bedtimes among children in the ECLS-K:

H1a Children living in neighborhoods with a high level of disorder will tend to have later bedtimes than children in neighborhoods without substantial disorder.

H1b Children living in neighborhoods with demographic disadvantages (e.g., a high percentage of female-headed households) will tend to have later bedtimes than children in neighborhoods without demographic disadvantages.

H1c Children living in neighborhoods with socioeconomic disadvantages (e.g., a high percentage of adults without 
a high school diploma) will tend to have later bedtimes than children in neighborhoods without socioeconomic disadvantages.

\section{Methods}

To test these hypotheses, we estimated a series of nested multilevel linear regression models with ECLS-K data. We describe these methods in detail below.

\section{Data}

We used data from the 19981999 ECLS-K, a nationally representative sample of US kindergarteners. The ECLS-K utilized a multistage probability sampling design; the primary sampling units (PSUs) were areas of counties or groups of counties. ${ }^{31}$ From this collection of counties, the ECLS-K selected 100 PSUs, resulting in a sample of 21,260 kindergarteners from 1,280 schools. Subsequently, ECLS-K personnel collected information about each kindergartener through parent, teacher, and school administrator interviews, as well as direct child assessments. The 19981999 ECLS-K is the most recent, nationally representative study with data on sleep that links kindergarteners to their residential locations, which were geocoded using Geographic Information System (GIS) software. ${ }^{32}$ Following prior research using ECLS-K data ${ }^{33}$ and other data sources, ${ }^{20,34}$ we merged ECLS-K data with US Census 2000 data at the tract level to examine the effects of neighborhood characteristics on children's sleep.

We relied on round 2 of the ECLS-K because data on children's bedtimes were not collected from parents in round 1. Most parent interviews (which collected bedtime data) were conducted by telephone from March to early June 1999, ${ }^{31}$ a period of time when school was in session for a large majority of kindergarteners. Although the exact interview date is not provided to data users, ECLS-K documentation indicates that fewer than $3 \%$ of parent interviews were conducted after June 15 . Round 2 included 6,392 census tracts with 2.8 children, on average, per tract (range: 1-23); 3,680 of these census tracts contained only one child. ${ }^{32}$ Simulation analyses indicate that, when the number of tracts is "large" ( $n>450)$, "neither fixed nor random components 
[are] affected by small group size, even when 90\% of tracts [have] only 1 individual per tract." 35 From this sample of 18,500 kindergarteners with tract information, parent interview information was available for 17,513 children. However, some of these children had missing data for one or more variables used in our analyses. Consequently, our analytical sample size for latest bedtime was 16,936, representing $97 \%$ of all kindergarteners with tract and parent information in round 2 of the ECLS-K. Because approximately $10 \%$ of parents in the ECLS-K did not report regular bedtimes, the sample of kindergarteners with a regular bedtime was 15,222.

\section{Measures}

\section{Outcome variables}

The 2 outcome variables in our study are the child's regular and latest bedtime during the week, as reported by a parent. Interviewers asked parents "About what time does [CHILD] usually go to bed?" for weeknights during the school year, and then "What is the latest time [CHILD] goes to bed on weekdays?" Prior research has shown strong associations between parent-reported bedtime and actigraphic measures of sleep onset $(r=0.87 ; P<.0005)$ and sleep duration $(r$ $=0.72 ; P<.0005)$ among kindergarteners. ${ }^{8}$ Moreover, evidence suggests that bedtimes affect sleep quality in early life, even when accounting for sleep duration. ${ }^{36,37}$ Due to a small number of atypical parent responses, we restricted earliest bedtime to 6:00 p.m. and latest bedtime to 2:00 a.m. To create continuous variables from reported bedtimes, we recoded each bedtime into the number of minutes past 6:00 p.m. Therefore, if a child went to bed at 6:00 p.m., we entered a value of o; if s/he went to bed at 2:00 a.m., we entered a value of 480 . The 2 variables approximated normal distributions, ranging between $0-420$ and $30-480$ for regular and latest bedtimes, respectively.

\section{Predictor variables}

We included measures of sex, race/ethnicity, and family type to represent the demographic characteristics of each child. In the ECLSK, sex is a binary measure; we used male as the reference category. The ECLS-K includes separate measures of race and ethnicity, which we combined into a single variable with the following categories: nonHispanic white (reference category), non-Hispanic black, Hispanic, 
non-Hispanic Asian (hereafter white, black, Hispanic, and Asian), and a final category consisting of all other races/ethnicities, including kindergarteners with more than one race. Although it would have been instructive to include separate categories for Native Hawaiian or other Pacific Islander and American Indian or Alaskan Native, the ECLS-K has a relatively small number of children from those groups. We categorized family type into two parents, single parent, or other family type, with two-parent family serving as the reference category.

To assess socioeconomic status, we used ECLS-K measures of annual household income and mother's educational attainment. We recoded household income into a 4-level ordinal variable, ranging from less than $\$ 25$, 000 (reference category) to $\$ 75$, o0o or more. For mother's educational attainment, we collapsed the ECLS-K variable with 22 categories into a 4-level ordinal variable: less than high school, a high school diploma or equivalent, some college or vocational school, and a bachelor's degree or greater.

We assessed neighborhood conditions via parent perceptions and census tract characteristics. Parents of ECLS-K children provided subjective neighborhood assessments based on their perceptions about problems with safety, garbage, selling or using of drugs, burglary, violent crime, and vacant housing. For each of these issues, response options were "big problem" = 2, "somewhat of a problem" = 1, and "no problem" = o. We constructed a perceived neighborhood disorder scale by summing responses across these 6 questions. Because sensitivity analyses indicated the presence of nonlinear associations with our outcome variables, we categorized the scale into "no disorder" for responses of o, "some disorder" for responses between 1 and 5, and "major disorder" for responses of 6 and greater.

For each census tract in the ECLS-K, we included demographic and socioeconomic indicators from the 2000 US Census to evaluate these characteristics at the neighborhood level. We included 3 measures of neighborhood demographic characteristics: percentage of residents who are non-Hispanic black, percentage of residents who are foreign born, and percentage of households that are female-headed with children. Although these variables can confer benefits to residents (e. g., comradery), they are also associated with neighborhood disadvantages such as social fragmentation and amenity deficiencies. For instance, prior research has found that as the percentage of foreign-born residents increases, neighborhood walkability, safety, social 
cohesion, and civic engagement decreases. ${ }^{38}$ We also included 3 measures of neighborhood socioeconomic status: percentage of residents aged 25 and older with less than a high school degree, percentage of residents aged 25 and older with a master's degree or greater, and a neighborhood economic stress scale. Following prior research, ${ }^{39}$ we constructed this scale by summing 3 census variables: percentage of households receiving public assistance, percentage of adult residents who are unemployed, and percentage of households below the poverty threshold. Higher scores on this scale indicate higher levels of neighborhood economic stress.

\section{Analytical strategy}

To account for the clustering of kindergarteners within census tracts (neighborhoods), we estimated a series of random intercept multilevel models using maximum likelihood with the mixed suite in STATA 14.1.40 In these models, we estimated fixed effect coefficients for predictor variables at the individual and neighborhood levels, as well as random effects to assess individual and neighborhood-level heterogeneity. Using common notation for multilevel models, ${ }^{41}$ we express our complete multilevel model with multiple individual level $\left(x_{p}\right)$ and neighborhood-level $\left(z_{q}\right)$ variables as follows:

$$
Y_{i j}=\gamma_{\mathrm{oo}}+\gamma_{10} x_{1 i j}+\ldots+\gamma_{p o} x_{p i j}+\gamma_{\mathrm{o} 1} z_{1 j}+\ldots+\gamma_{\mathrm{oq}} z_{q j}+U_{\mathrm{oj}}+R_{i j}
$$

where $Y_{i j}$ is regular (or latest) bedtime for child $i$ in neighborhood $j$; $Y_{\mathrm{oo}}$ is the expected bedtime for a random kindergartener from a randomly selected neighborhood; $x_{1}, \ldots, x_{p}$ are individual-level predictors, with regression parameters $\gamma_{h o}(h=1, \ldots, p) ; z_{1}, \ldots, z_{q}$ are neighborhood-level predictors, with regression parameters $Y_{\mathrm{o} h}(h=1, \ldots$, $q) ; U_{\mathrm{oj}}$ are neighborhood-level residuals, with variance $\tau_{\mathrm{o}}^{2}$ and $\mathrm{R}_{\mathrm{ij}}$ are individual-level residuals, with variance $\sigma^{2}$.

We estimated 5 nested models for each outcome variable. In the baseline model (Model 1), we included individual-level demographic characteristics. In Model 2, we added indicators of household income and mother's educational attainment. In Model 3, we included the perceived neighborhood disorder scale. In Models 4-5, we added tractlevel demographic and socioeconomic characteristics, respectively. 
Because tract-level variables are continuous, we centered them on their grand means before entering them into Models 4-5. Consistent with prior research on neighborhood effects in the ECLSK, ${ }^{42}$ we estimated unweighted regression coefficients because the ECLS-K does not provide sampling weights for census tracts. Stapleton and Kang ${ }^{43}$ previously found small design effects in the ECLS-K, with "minimal departure from 1.0" in most instances (p. 18).

In empty models (i.e., no predictor variables), we detected significant variability $((\mathrm{P}<.001)$ in regular and latest bedtimes at the neighborhood $\left(\tau_{\mathrm{o}}^{2}\right)$ and individual levels $\left(\sigma^{2}\right)$. Using residual variances, we calculated intraclass correlation coefficients $\left(I C C=\tau_{\mathrm{o}}^{2} /\left(\tau_{\mathrm{o}}^{2}+\sigma^{2}\right)\right)$ to determine how much variability in children's bedtimes was attributable to neighborhoods. For regular and latest bedtimes, the ICC was 0.12 and 0.09 , respectively. This means that $12 \%$ of total variability in regular bedtimes was due to differences between neighborhoods, and the remaining $88 \%$ was due to differences among kindergarteners within neighborhoods. Although slightly less variability in latest bedtimes was attributable to neighborhood differences, there was nevertheless ample between and within-neighborhood variability for both outcomes to warrant a multilevel modeling approach to ECLS-K data.

\section{Results}

\section{Descriptive statistics}

Average regular and latest weekday bedtimes were 8:32 p.m. (152 minutes past 6 p.m.) and 9:15 p.m. (195 minutes past 6 p.m.) with standard deviations of 37 and 45 minutes, respectively. Table 1 presents descriptive statistics for all individual-level variables used to predict these outcomes. Differences between latest bedtime ( $\mathrm{n}=$ $16,936)$ and regular bedtime $(n=15,222)$ samples were slight; the regular bedtime sample was less diverse, with higher levels of socioeconomic status, and lower levels of neighborhood disorder. Because our estimates are unweighted, they are intended to describe ECLSK samples rather than the US population. Nevertheless, the ECLS$\mathrm{K}$ data exhibit sex balance and considerable racial/ethnic diversity. Whereas a large majority (about $78 \%$ ) of children in this sample 
Table 1 Descriptive statistics for individual characteristics, ECLS-K 1998-1999

\begin{tabular}{|c|c|c|}
\hline Variable & $\begin{array}{r}\text { Latest } \\
\text { weekday bedtime } \\
(n=16,936)\end{array}$ & $\begin{array}{r}\text { Regula } \\
\text { weekday bedtim } \\
(n=15,222\end{array}$ \\
\hline \multicolumn{3}{|l|}{ Sex } \\
\hline Male & $50.77 \%$ & $50.74 \%$ \\
\hline Female & $49.23 \%$ & $49.26 \%$ \\
\hline \multicolumn{3}{|l|}{ Race/Ethnicity } \\
\hline Non-Hispanic white & $57.82 \%$ & $60.43 \%$ \\
\hline Non-Hispanic black & $14.47 \%$ & $13.65 \%$ \\
\hline Hispanic & $17.91 \%$ & $16.65 \%$ \\
\hline Non-Hispanic Asian & $5.76 \%$ & $5.37 \%$ \\
\hline Other, non-Hispanic & $4.03 \%$ & $3.89 \%$ \\
\hline \multicolumn{3}{|l|}{ Household type } \\
\hline 2 parents & $78.06 \%$ & $78.94 \%$ \\
\hline 1 parent & $20.12 \%$ & $19.27 \%$ \\
\hline Other & $1.82 \%$ & $1.79 \%$ \\
\hline \multicolumn{3}{|l|}{ Income } \\
\hline$<\$ 25,000$ & $27.49 \%$ & $25.59 \%$ \\
\hline$\$ 25,000-44,999$ & $23.52 \%$ & $23.43 \%$ \\
\hline$\$ 45,000-74,999$ & $26.08 \%$ & $26.87 \%$ \\
\hline$\$ 75,000$ & $22.91 \%$ & $24.11 \%$ \\
\hline \multicolumn{3}{|l|}{ Mother's education } \\
\hline$<$ High school & $13.10 \%$ & $11.58 \%$ \\
\hline High school diploma/equivalent & $29.19 \%$ & $28.75 \%$ \\
\hline Some college/vocational school & $32.56 \%$ & $33.28 \%$ \\
\hline Bachelor's degree or greater & $25.15 \%$ & $26.40 \%$ \\
\hline \multicolumn{3}{|l|}{ Perceived neighborhood disorder } \\
\hline No disorder & $60.65 \%$ & $62.69 \%$ \\
\hline Some disorder & $36.78 \%$ & $35.03 \%$ \\
\hline Major disorder & $2.57 \%$ & $2.29 \%$ \\
\hline
\end{tabular}

belonged to two-parent households, about 1 in 5 children lived in a single-parent home. Each of the 4 household income categories contained roughly one-quarter of kindergarteners in the sample, with slightly more households reporting low income $(<\$ 25,000)$ than high income $(\geq \$ 75,000)$. Nearly 6 in 10 mothers reported some college or more education; only $13 \%$ of mothers in the entire sample indicated that they had not completed high school. Although 4 in 10 mothers reported some level of neighborhood disorder, only a small minority (about 3\%) in this sample perceived major disorder in the vicinity of their home.

As shown in Table 2, kindergarteners in the ECLS-K resided in neighborhoods where, on average, relatively small proportions of the 
Table 2 Descriptive statistics for neighborhood characteristics, ECLS-K 1998-1999

\begin{tabular}{|c|c|c|c|c|}
\hline \multirow[b]{2}{*}{ Variable } & \multicolumn{2}{|c|}{$\begin{array}{l}\text { Latest weekday } \\
\text { bedtime }(n=16,936)\end{array}$} & \multicolumn{2}{|c|}{$\begin{array}{c}\text { Regular weekday } \\
\text { bedtime }(n=15,222)\end{array}$} \\
\hline & Mean & $\begin{array}{c}\text { Standard } \\
\text { Deviation (Range) }\end{array}$ & Mean & $\begin{array}{c}\text { Standard } \\
\text { Deviation (Range) }\end{array}$ \\
\hline \multicolumn{5}{|l|}{ Neighborhood demographics } \\
\hline Percent non-Hispanic black & 13.76 & $22.58(0-100)$ & 12.79 & $21.93(0-100)$ \\
\hline Percent foreign born & 11.94 & $14.48(0-83.78)$ & 11.40 & $14.04(0-83.78)$ \\
\hline Percent female head of household with children & 7.97 & $5.89(0-55.58)$ & 7.72 & $5.71(0-55.58)$ \\
\hline \multicolumn{5}{|l|}{ Neighborhood socioeconomic status } \\
\hline Percent age $25+$ with less than high school degree & 21.10 & $14.86(0-81.95)$ & 20.33 & $14.44(0-81.95)$ \\
\hline Percent age $25+$ with a master's degree or greater & 8.69 & $8.29(0-60.71)$ & 8.92 & $8.41(0-60.71)$ \\
\hline Neighborhood economic stress scale & 7.71 & $6.38(0.36-49.77)$ & 7.39 & $6.15(0.36-49.77)$ \\
\hline
\end{tabular}

population were black, foreign born, or female household heads with children. However, large standard deviations and ranges for these measures show considerable demographic diversity across neighborhoods in the ECLS-K. With respect to neighborhood socioeconomic status, children resided in neighborhoods where, on average, about 21\% of the adult population (those aged 25 or older) lacked a high school degree and $9 \%$ of the adult population had a master's degree or more education. Although kindergarteners tended to live in neighborhoods with low scores on the economic stress scale, there was considerable variability in economic stress across neighborhoods in these samples.

\section{Individual-level demographic characteristics}

Model 1 in Table 3 (regular bedtime) and Table 4 (latest bedtime) provided strong support for H1a. Every racial/ethnic minority group of kindergarteners in our study went to bed later, on average, than white children $(P<.001$ in every instance). On average, parents of black, Hispanic, and Asian children reported regular weekday bedtimes that were approximately 7, 11, and 26 minutes later, respectively, than parents of white children. These racial/ethnic discrepancies were all somewhat larger for latest weekday bedtimes. Although the magnitude of racial/ethnic differences attenuated with the addition of other predictor variables in Models 2-5, they all remained statistically significant. Nevertheless, it is interesting to point out that black-white bedtime disparities declined most precipitously in Model 4 
Table 3 Hierarchical linear models for regular weekday bedtime, ECLS-K 1998-1999 $(n=15,222)$

\begin{tabular}{|c|c|c|c|c|c|c|c|c|c|c|}
\hline \multirow[b]{2}{*}{ Fixed effects } & \multicolumn{2}{|c|}{ Model 1} & \multicolumn{2}{|c|}{ Model 2} & \multicolumn{2}{|c|}{ Model 3} & \multicolumn{2}{|c|}{ Model 4} & \multicolumn{2}{|c|}{ Model 5} \\
\hline & $\beta$ & se & $\beta$ & se & $\beta$ & se & $\beta$ & se & $\beta$ & se \\
\hline Intercept & $147.77^{\star \star \star}$ & 0.53 & $151.37^{\star \star \star}$ & 1.16 & $150.42^{* \star \star}$ & 1.21 & $150.66^{\star \star \star}$ & 1.21 & $150.22^{\star \star \star}$ & 1.23 \\
\hline \multicolumn{11}{|l|}{ Individual characteristics } \\
\hline \multicolumn{11}{|l|}{ Race (reference $=$ non-Hispanic white) } \\
\hline Non-Hispanic black & $6.93^{\star \star \star}$ & 0.99 & $6.63^{* * *}$ & 1.00 & $6.37^{\star \star \star}$ & 1.01 & $3.70^{* *}$ & 1.21 & $3.70^{* *}$ & 1.21 \\
\hline Hispanic & $10.63^{* \star *}$ & 0.86 & $9.57^{\star \star \star}$ & 0.90 & $9.35^{\star \star \star}$ & 0.90 & $7.77^{\star \star \star}$ & 0.99 & $7.57^{\star \star \star}$ & 0.99 \\
\hline Non-Hispanic Asian & $25.59^{* \star \star}$ & 1.33 & $25.63^{\star \star \star}$ & 1.34 & $25.43^{\star \star \star}$ & 1.34 & $24.08^{\star \star \star}$ & 1.39 & $24.53^{\star \star \star}$ & 1.40 \\
\hline Other, non-Hispanic & $5.70^{* * *}$ & 1.54 & $5.43^{\star \star *}$ & 1.54 & $5.24^{\star *}$ & 1.54 & $4.51^{\star \star}$ & 1.55 & $4.75^{\star *}$ & 1.55 \\
\hline \multicolumn{11}{|l|}{ Sex $($ reference $=$ male $)$} \\
\hline Female & $-1.60^{* *}$ & 0.57 & $-1.60^{* *}$ & 0.57 & $-1.59^{* *}$ & 0.57 & $-1.56^{* *}$ & 0.57 & $-1.57^{\star \star}$ & 0.57 \\
\hline \multicolumn{11}{|l|}{ Family type (reference = two parents) } \\
\hline One parent & 0.51 & 0.78 & 0.32 & 0.84 & 0.30 & 0.84 & 0.12 & 0.84 & 0.27 & 0.84 \\
\hline Other & -1.29 & 2.19 & -1.92 & 2.20 & -1.85 & 2.20 & -2.06 & 2.20 & -2.13 & 2.20 \\
\hline \multicolumn{11}{|l|}{ Income (reference $=<\$ 25,000$ ) } \\
\hline$\$ 25,000-44,999$ & & & -0.16 & 0.88 & -0.01 & 0.89 & 0.19 & 0.89 & 0.18 & 0.89 \\
\hline$\$ 45,000-74,999$ & & & 1.06 & 0.95 & 1.35 & 0.96 & 1.69 & 0.96 & 1.76 & 0.97 \\
\hline$\$ 75,000$ and greater & & & 1.48 & 1.07 & 1.85 & 1.08 & $2.26^{*}$ & 1.09 & $2.65^{*}$ & 1.11 \\
\hline \multicolumn{11}{|c|}{ Mother's educational attainment (reference $=<$ high school) } \\
\hline High school degree/equivalent & & & $-2.03^{*}$ & 1.05 & -1.90 & 1.06 & -1.50 & 1.06 & -1.30 & 1.06 \\
\hline Some college/vocational school & & & $-4.80^{\star \star \star}$ & 1.08 & $-4.61^{\star \star \star}$ & 1.08 & $-4.19^{\star \star \star}$ & 1.08 & $-3.89^{\star \star \star}$ & 1.09 \\
\hline Bachelor's degree or greater & & & $-6.45^{* \star *}$ & 1.21 & $-6.23^{* * *}$ & 1.21 & $-5.70^{* \star *}$ & 1.22 & $-5.11^{* \star *}$ & 1.23 \\
\hline \multicolumn{11}{|c|}{ Perceived neighborhood disorder (reference $=$ no disorder) } \\
\hline Some disorder & & & & & $1.73^{\star \star}$ & 0.64 & 1.21 & 0.64 & $1.25^{\star}$ & 0.64 \\
\hline Major disorder & & & & & 2.64 & 2.01 & 1.07 & 2.03 & 1.28 & 2.04 \\
\hline \multicolumn{11}{|l|}{ Neighborhood characteristics } \\
\hline \multicolumn{11}{|l|}{ Neighborhood demographics } \\
\hline Percent non-Hispanic black & & & & & & & 0.05 & 0.02 & $0.06^{*}$ & 0.03 \\
\hline Percent foreign born & & & & & & & $0.09^{* *}$ & 0.03 & 0.05 & 0.03 \\
\hline Percent female head of household with & children & & & & & & 0.17 & 0.09 & 0.20 & 0.12 \\
\hline \multicolumn{11}{|c|}{ Neighborhood socioeconomic status } \\
\hline Percent age $25+$ with less than high scl & hool degree & & & & & & & & $0.15^{* *}$ & 0.05 \\
\hline Percent age $25+$ with a master's degree & e or greater & & & & & & & & -0.01 & 0.05 \\
\hline Neighborhood economic stress scale & & & & & & & & & $-0.29^{*}$ & 0.13 \\
\hline Random effects & Estimate & se & Estimate & se & Estimate & se & Estimate & se & Estimate & se \\
\hline Variance among individuals & 1160.67 & 14.78 & 1158.27 & 14.74 & 1158.17 & 14.73 & 1156.82 & 14.72 & 1156.74 & 14.71 \\
\hline Variance among neighborhoods & 129.06 & 10.11 & 127.44 & 10.04 & 126.58 & 10.01 & 125.40 & 9.96 & 123.97 & 9.93 \\
\hline \multirow{2}{*}{$\begin{aligned} \text { Measures of fit } & -\mathrm{AIC} \\
& -\chi^{2}\end{aligned}$} & 151,909 & & 151,879 & & 151,874 & & 151,854 & & 151,848 & \\
\hline & $477.17^{\star * * *}$ & & $521.42^{k * *}$ & & $530.26^{* * *}$ & & $557.74^{* * *}$ & & $571.41^{\text {t*kt }}$ & \\
\hline
\end{tabular}


Table 4 Hierarchical linear models for latest weekday bedtime, ECLS-K $19981999(n=16,936)$

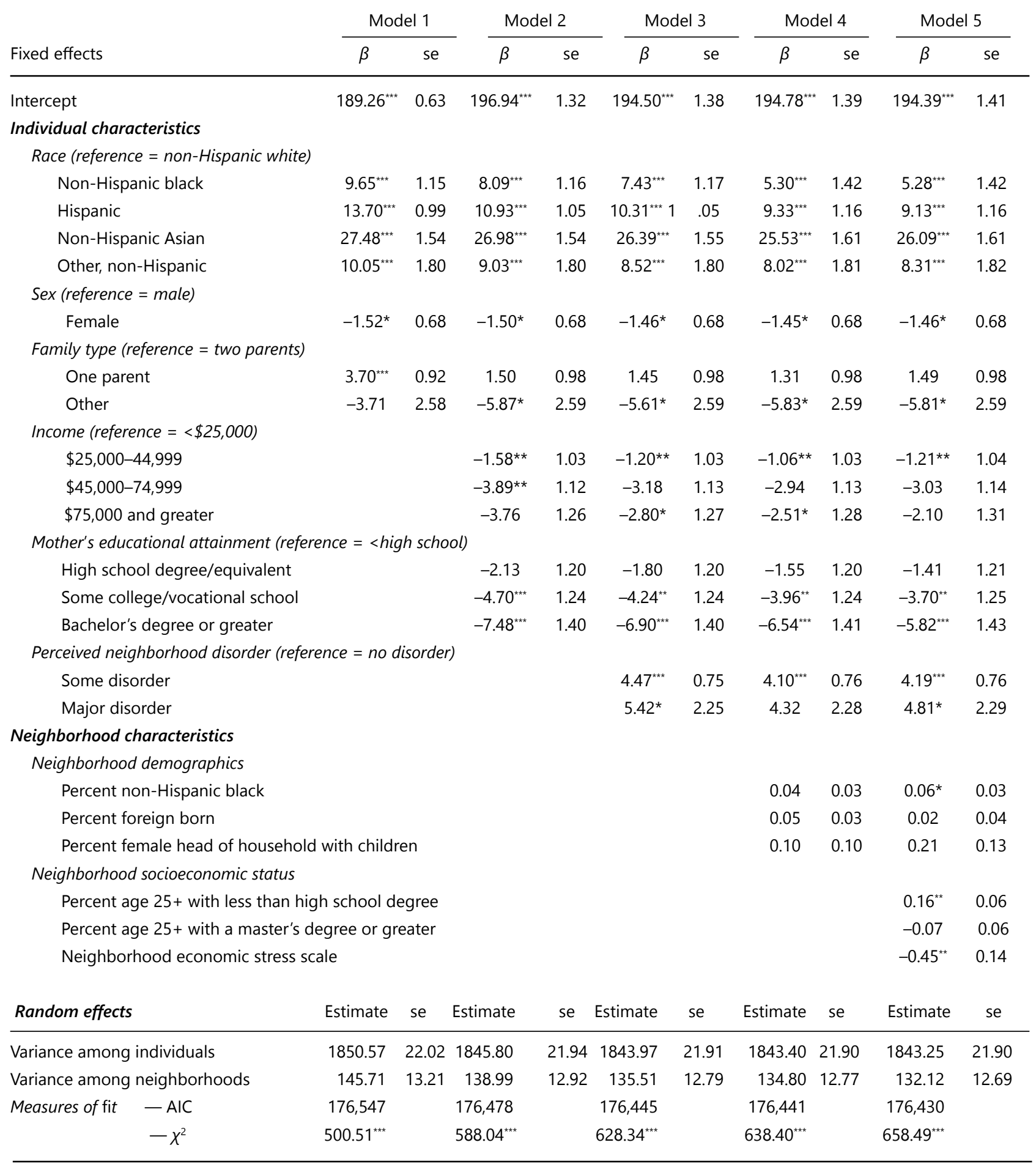


after tract-level demographic variables were added to the analysis. For instance, holding neighborhood conditions constant reduced blackwhite disparities in regular bedtimes by $42 \%$ (i.e., from $6.37 \mathrm{~min}-$ utes in Model 3 to 3.70 minutes in Models 4 5), suggesting that blackwhite sleep inequalities may operate to a considerable extent through neighborhood conditions.

Model 1 also supported H1b, as male children had significantly later regular (Table 3) and latest bedtimes (Table 4) than female children. While significant sex effects persisted across all subsequent models, they were small in magnitude, with females going to bed less than 2 minutes earlier than males, on average. Contrary to our expectations, Model 1 provides only provisional support for H1c. Family type (one versus two-parent households) did not significantly affect children's regular bedtimes (Table 3). Although latest bedtimes for kindergarteners in one-parent families were significantly later than kindergarteners in two-parent families (Table 4), the effect was modest (less than 4 minutes in Model 1) and largely explained in Model 2 through socioeconomic factors.

\section{Individual-level socioeconomic characteristics}

Contrary to $\mathrm{H} 2 \mathrm{a}$, parents in low-income households $(<\$ 25,000)$ did not report significantly later regular bedtimes for their kindergarteners than parents in higher-income households (Model 2, Table 3). Also contrary to $\mathrm{H} 2 \mathrm{a}$, a small but significant positive effect $(\beta=2.26$, $P<$.05) emerged for children from the highest-income households ( $>$ \$75,000) in Model 4-indicating that they had later regular bedtimes than children from low-income households, after accounting for demographic differences across neighborhoods. However, results for latest bedtime were consistent with hypothesis H2a (Model 2, Table 4). Relative to kindergarteners from the lowest income group, latest bedtimes were about 4 minutes earlier, on average, for kindergarteners in households with $\$ 45,000$ or more in annual income. Interestingly, this effect was not linear, as $\$ 45,00074,999$ was consistently the most advantaged income group in Models 2-5.

Results from Model 2 provided strong support for $\mathrm{H} 2 \mathrm{~b}$, as mother's educational attainment was significantly associated with regular (Table 3) and latest (Table 4) bedtimes. Moreover, we found clear evidence of a gradient effect for both outcomes; mothers with college 
degrees reported the earliest bedtimes for their children, followed first by mothers with some college and then by mothers who completed high school but did not attend college. Despite modest attenuation after the addition of neighborhood factors, significantly earlier regular and latest bedtimes among kindergarteners with well-educated mothers persisted in Models 3-5.

\section{Perceived neighborhood disorder}

Overall, Model 3 supported H3a (Tables 3 and 4). Parents who perceived neighborhood disorders tended to report significantly later regular (Table 3) and latest (Table 4) bedtimes for their children than parents who did not perceive any disorders. Although the effect of major neighborhood disorder on regular bedtime was not statistically significant ( $\beta=2.64, P>0.05)$, this was likely a consequence of the relatively small number of kindergarteners in this group. The addition of tract-level neighborhood characteristics in Models 45 caused substantial attenuation in the associations between perceived neighborhood disorder and regular bedtime (Table 3). Although we also observed some attenuation in associations between neighborhood disorder and latest bedtime in Models 4-5 (Table 4), these coefficients were generally more resistant to change. Even after including all neighborhood-level variables (Model 5), parents from neighborhoods with "some" or "major" disorder reported latest weekday bedtimes that were 4-5 minutes later, on average, than parents from neighborhoods with no disorder.

\section{Neighborhood-level demographic characteristics}

Estimates from Model 4 provided limited support for H3b. In Table 3, Model 4 revealed a significant association between regular bedtime and the percentage of foreign-born individuals in a neighborhood ( $\beta$ $=0.09, P<.01)$. One interpretation of this coefficient is that the expected regular bedtime for children from neighborhoods with $40 \%$ foreign-born residents is 2.7 minutes later than children from neighborhoods with 10\% foreign-born residents. This coefficient was cut in half and rendered insignificant after neighborhood socioeconomic conditions were added in Model 5 (Table 3). Moreover, the percentage of foreign-born individuals was not significantly associated with latest bedtime in any model (Table 4 ). 
Also contrary to $\mathrm{H} 3 \mathrm{~b}$, in Model 4 we did not detect significant associations between the percentage of black residents or the percentage of single mothers and either regular (Table 3 ) or latest (Table 4) bedtimes. Note that the appearance of a $t$-statistic $>2$ for the percentage of black residents in Model 4 of Table 3 is an artifact of rounding; actual model estimates were $\beta=0.0474$, se $=0.0247, t=1.92$, and $P=$ .055. However, this marginally-significant effect achieved the traditional criterion of significance $(P<.05)$ after neighborhood socioeconomic status variables were introduced in Model 5 . This was true for both regular and latest bedtimes $(\beta=0.06, P<.05)$. To illustrate this effect, the expected regular and latest bedtimes for kindergarteners from neighborhoods with 40\% black residents were 1.8 minutes later than kindergarteners from neighborhoods with 10\% black residents.

\section{Neighborhood-level socioeconomic characteristics}

Results for Model 5 were broadly similar for both regular (Table 3) and latest (Table 4) bedtimes. In support of H3c, we found statistically significant associations between these outcomes and the percentage of adults (persons aged 25 or older) without high school degrees. In keeping with prior illustrations, the expected regular and latest bedtimes for children from neighborhoods where $40 \%$ of adults lacked a high school degree were about 5 minutes later than children from neighborhoods where $10 \%$ of adults did not complete high school. However, contrary to $\mathrm{H} 3 \mathrm{c}$, we found no bedtime advantages for kindergarteners from neighborhoods with particularly well-educated adult populations. Also contrary to our expectations, we discovered significant negative associations between the neighborhood economic stress scale and both regular and latest bedtimes. This means that children from neighborhoods characterized by high levels of economic stress tended to have earlier bedtimes than other children. Finally, controlling for neighborhood-level socioeconomic characteristics did not weaken the effect of percent black, as we might have anticipated, but rather caused it to increase and become statistically significant for both outcomes. This finding indicates that racial concentration affects bedtimes through environmental, cultural, or other neighborhood differences that are not directly tied to local economic conditions. 


\section{Discussion}

Given ample evidence linking sleep to wellbeing during early childhood, it is important to understand the determinants of sleep outcomes at this stage of the life course. In this study, we examined the effects of individual and neighborhood-level characteristics on the regular and latest weekday bedtimes of kindergarten-aged children, using data from the ECLS-K Class of 1998 1999. While our multilevel models indicated that most of the variation in bedtimes was due to differences among kindergarteners within neighborhoods, they also revealed significant variability between neighborhoods. The neighborhood effects we report in this investigation may be conservative estimates, as prior research has detected stronger connections between sleep and longitudinal measures of neighborhood characteristics, relative to cross-sectional measures. ${ }^{20}$

Consistent with hypotheses $\mathrm{H} 1 \mathrm{a}$ and $\mathrm{H} 1 \mathrm{~b}$, our analyses showed that sex and race/ethnicity were associated with children's bedtimes. That is, parents of male children in the ECLS-K reported later regular and latest bedtimes than parents of female children, which is consistent with some prior research. ${ }^{21,22}$ Although the sex difference we observe is small (about 1.5 minutes, on average) and not clinically relevant on any given night, it has the potential to accumulate over multiple weeknights. Prior research has indicated that incremental but chronic sleep loss has adverse effects on diet and body habitus in early childhood. ${ }^{44}$ Research has also shown that females tend to prefer earlier bed and wake times than males, but this divergence does not occur until the teen years. 45 Therefore, it seems likely that sex differences in children's bedtimes reflect societal gender norms about parenting, rather than biological needs of children. Indeed, previous work has found that parents tend to be more permissive with boys than girls across a wide range of activities, including dietary habits, screen use, and responses to night awakenings. ${ }^{46}$

Additionally, parents of black, Hispanic, and Asian children reported later bedtimes than their white counterparts. This finding is consistent with previous research indicating that black and Hispanic children tend to have later and less consistent bedtimes than white children. ${ }^{14,15}$ Although racial/ethnic disparities persisted across all of our models, we found that individual-level socioeconomic conditions and perceptions of neighborhood disorder explained some of the 
discrepancies between racial/ethnic minority and white children in the ECLS-K. Prior research has documented racial disparities in sleep ${ }^{12,47}$ but relatively few studies have examined how neighborhood characteristics might explain these disparities. ${ }^{48,49}$ In addition to neighborhood disorder, neighborhood-level demographic characteristics accounted for a portion of racial/ethnic bedtime disparities in our models, especially among black children. These findings are important, as they suggest that black-white sleep disparities during childhood are partly rooted in dissimilar environmental conditions.

Notably, parents of Asian kindergarteners reported bedtimes that were, on average, about 25 minutes later than parents of white kindergarteners. Consistent with this finding, a review of scholarship on childhood sleep patterns found that children from Asian countries had significantly shorter sleep durations than children from European countries. ${ }^{50}$ However, relatively little is currently known about the mechanisms responsible for disparate sleep outcomes among Asian children. We speculate that the large Asian-white disparity in bedtimes may be related to cultural differences in sleep practices, as demographic and socioeconomic covariates at both the individual and neighborhood levels in the ECLS-K did not appreciably reduce it. Cultural differences in sleep practices have been proposed as potential explanations, but not tested empirically, highlighting the need for continued research in this area. ${ }^{12,15,51}$

Contrary to our expectation in H1c, single-parent households did not report significantly later regular bedtimes than two-parent households. Although a previous study found that single mother households "are least likely to engage in regular use of bedtime routines" (p. 5), ${ }^{34}$ this same study found no differences in the hour of bedtime between family types in multivariate models. Moreover, the difference we observed between one and two-parent households in latest bedtimes was reduced by 6o\% (and rendered statistically insignificant) when household income and mother's education were taken into account. This suggests that differences in children's sleep across family types reflect poorer socioeconomic conditions experienced by single-parent households.

In our final multivariable models, we detected significant associations between family socioeconomic status and bedtimes among children in the ECLS-K-consistent with $\mathrm{H} 2 \mathrm{a}$ and $\mathrm{H} 2 \mathrm{~b}$. That is, as household income and mother's educational attainment increased, 
kindergarteners tended to go to bed at earlier times. Our findings are consistent with prior research connecting poor sleep outcomes in childhood to socioeconomic disadvantage. ${ }^{11,13,14,47}$ Although individuallevel socioeconomic effects often persisted across our models, they also tended to weaken after introducing neighborhood characteristics. This suggests that individual-level socioeconomic disparities in childhood sleep are partly attributable to disparate demographic and socioeconomic environmental contexts. Other mechanisms that may link family socioeconomic status to children's sleep include pre-sleep worries, disruptive conditions (e.g., an uncomfortable bed or ambient noise), and parental knowledge about healthy sleep habits. ${ }^{11,15,52}$ Future studies should explore the mediating role of these potential mechanisms, as well as strategies employed by children to cope with adverse sleep conditions.

In addition to individual-level effects, our investigation found that perceived neighborhood disorder (H3a), neighborhood-level demographic conditions ( $\mathrm{H}_{3} \mathrm{~b}$ ), and neighborhood socioeconomic conditions (H3c) affected bedtimes among children in the ECLS-K. Overall, these associations were either consistent with our hypotheses or not statistically significant. But contrary to our expectations in $\mathrm{H} 3 \mathrm{c}$, we found that high levels of neighborhood economic stress were associated with earlier regular and latest bedtimes. Our study was not the first to make this interesting discovery. Previously, Troxel et al found that adolescents living in impoverished neighborhoods tended to go to bed earlier than more advantaged adolescents. ${ }^{29}$ However, this same study found that neighborhood poverty did not affect adolescents' total sleep time, perhaps due to sleep disruptions or early awakenings. These findings suggest that parents in economically stressed neighborhoods may use early bedtimes as a strategy to help offset sleep challenges (e.g., ambient noise) posed by their environments.

Future research should also endeavor to understand in more detail the specific mechanisms that link individual and neighborhood characteristics to children's sleep outcomes and bedtime routines. For instance, while racial/ethnic bedtime disparities were partly explained by neighborhood conditions in our study, large discrepancies nevertheless persisted in our final models. To help explain those discrepancies, researchers should consider the role of individual-level constraints, attitudes, and behaviors, such as parents' work schedules, homework expectations, and rules governing child behaviors near bedtime. Another 
area for future research to explore is the role of discriminatory experiences. A recently published meta-analysis of 17 studies found consistent evidence that racial/ethnic discrimination is associated with self-reported and objectively-measured sleep problems in adult, adolescent, and child samples. ${ }^{53}$ At the neighborhood level, future studies should consider potential mediators that are not available in the ECLS$\mathrm{K}$, such as ambient noise and contextual norms regarding bedtimes. Including these variables could help explain sleep patterns among children living in disadvantaged neighborhoods. Future studies could also consider how other contextual variables (e.g., school start times) affect regular and latest weekday bedtimes.

Our study has some notable limitations. First, ECLS-K data on bedtimes were parent-reported and therefore subjective in nature. Without objective sleep measures, we could not provide a comprehensive assessment of individual and neighborhood-level contributors to sleep outcomes among kindergarten-aged children. Second, perceived neighborhood disorder is also necessarily subjective and may not reflect objective environmental conditions. However, this limitation is counterbalanced by our inclusion of objective measures of neighborhood characteristics via tract data from the US Census. Third, our study is cross-sectional, which prohibits us from making causal inferences. In the future, researchers should consider how longitudinal and experimental study designs could elucidate causal pathways through which neighborhood conditions affect sleep outcomes. Fourth, although census tracts are commonly used to assess neighborhood effects in the health literature, they do not align perfectly with neighborhood boundaries. This measurement error likely biases associations between neighborhood conditions and sleep outcomes toward the null. Fifth, the age of the 19981999 ECLS-K could limit the generalizability of our findings. While one analysis of data from the Panel Study of Income Dynamics found no evidence of changing sleep patterns among U.S. children between 1998 and 2007,54 another meta-analysis found that sleep duration declined over the past century among children in various countries, including the United States. ${ }^{55}$ A recent study of US adults also found that the prevalence of short sleep duration increased and racial disparities in short sleep widened between 2013 and 2017. ${ }^{6}$ Moreover, even if parenting behaviors regarding the bedtimes of young children have remained stable over time, normative behaviors of children immediately preceding bedtime (e.g., exposure 
to blue light via various screen technologies) may have changed in ways that are detrimental to sleep quality. ${ }^{57}$ Should contemporary, nationally representative bedtime data among kindergarteners become available in the future, we encourage researchers to replicate and extend our study to address these potential issues.

\section{Conclusions}

Our study provides a novel scientific contribution to the literature on neighborhood environments and sleep issues during childhood. Through our investigation, we found that both individual and neighborhood-level characteristics help explain variation in bedtimes among kindergarten-aged children. These findings imply that reducing disparities in childhood sleep will require policies and programs that target not only individuals, but also the communities in which they reside. The efficacy of these programs will improve as future research delves farther into the questions that we have begun to explore. This highlights the importance of continuing research in this area, as sleep disparities during childhood are likely to have long lasting health effects among individuals from disadvantaged backgrounds.

\section{References}

1. National Sleep Foundation. Children and sleep. 2018; https://www. sleepfoundation.org/articles/children-and-sleep

2. Paruthi S, Brooks LJ, D'Ambrosio C, et al. Consensus statement of the American Academy of Sleep Medicine on the recommended amount of sleep for healthy children: methodology and discussion. J Clin Sleep Med. 2016;12:1549-1561.

3. Ohayon M, Wickwire EM, Hirshkowitz M, et al. National Sleep Foundation's sleep quality recommendations: first report. Sleep Health. 2017;3:6-19.

4. Snell EK, Adam EK, Duncan GJ. Sleep and the Body Mass Index and Overweight Status of Children and Adolescents. Child Dev. 2007;78:309-323.

5. Vaughn BE, Elmore-Staton L, Shin N, El-Sheikh M. Sleep as a support for social competence, peer relations, and cognitive functioning in preschool children. Behav Sleep Med. 2015;13:92-106.

6. Scharf RJ, Demmer RT, Silver EJ, Stein REK. Nighttime sleep duration and externalizing behaviors of preschool children. J Dev Behav Pediatr. 2013;34:384-391.

7. Haas S. Trajectories of functional health: the 'long arm' of childhood health and socioeconomic factors. Soc Sci Med. 2008;66:849-861. 
8. Tikotzky L, Sadeh A. Sleep patterns and sleep disruptions in kindergarten children. J Clin Child Adolesc Psychol. 2001;30:581-591.

9. Cairns A, Harsh J. Changes in Sleep Duration, Timing, and Quality as Children Transition to Kindergarten. Behav Sleep Med. 2014;12:507-516.

10. Kitsaras G, Goodwin M, Allan J, Kelly MP, Pretty IA. Bedtime routines child wellbeing \& development. BMC Public Health. 2018;18. 386-386.

11. Bagley EJ, Kelly RJ, Buckhalt JA, El-Sheikh M. What keeps low-SES children from sleeping well: the role of presleep worries and sleep environment. Sleep Med. 2015;16:496-502.

12. Crosby B, LeBourgeois MK, Harsh J. Racial differences in reported napping and nocturnal sleep in 2to 8-year-old children. Pediatrics. 2005;115(1 Suppl):225-232.

13. El-Sheikh M, Bagley EJ, Keiley M, Elmore-Staton L, Chen E, Buckhalt JA. Economic adversity and children's sleep problems: multiple indicators and moderation of effects. Health Psychol. 2013;32:849-859.

14. McLaughlin Crabtree V, Beal Korhonen J, Montgomery-Downs HE, Faye Jones V, O'Brien LM, Gozal D. Cultural influences on the bedtime behaviors of young children. Sleep Med. 2005;6:319-324.

15. Hale L, Berger LM, LeBourgeois MK, Brooks-Gunn J. Social and demographic predictors of preschoolers' bedtime routines. J Dev Behav Pediatr. 2009;30:394-402.

16. Milan S, Snow S, Belay S. The context of preschool children's sleep: racial/ ethnic differences in sleep locations, routines, and concerns. J Fam Psychol. 2007;21:20-28.

17. Phelan JC, Link BG, Tehranifar P. Social conditions as fundamental causes of health inequalities: theory, evidence, and policy implications. J Health Soc Behav. 2010;51 (Suppl). S28-40.

18. Singh GK, Kenney MK. Rising prevalence and neighborhood, social, and behavioral determinants of sleep problems in US children and adolescents, 2003-2012. Sleep Disord. 2013;2013: 394320.

19. Spilsbury JC, Storfer-Isser A, Kirchner HL, et al. Neighborhood disadvantage as a risk factor for pediatric obstructive sleep apnea. J Pediatr. 2006;149:342-347.

20. Sheehan C, Powers D, Margerison-Zilko C, McDevitt T, Cubbin C. Historical neighborhood poverty trajectories and child sleep. Sleep Health. 2018;4:127-134.

21. Smaldone A, Honig JC, Byrne MW. Sleepless in America: inadequate sleep and relationships to health and well-being of our nation's children. Pediatrics. 2007;119 (Suppl 1):S29-S37.

22. Wilson KE, Miller AL, Lumeng JC, Chervin RD. Sleep environments and sleep durations in a sample of low-income preschool children. J Clin Sleep Med. 2014;10:299-305.

23. Ross CE, Mirowsky J. Neighborhood disadvantage, disorder, and health. $J$ Health Soc Behav. 2001;42:258-276. 
24. Hale L, Hill TD, Burdette AM. Does sleep quality mediate the association between neighborhood disorder and self-rated physical health? Prev Med. 2010;51:275-278.

25. Hill TD, Burdette AM, Hale L. Neighborhood disorder, sleep quality, and psychological distress: testing a model of structural amplification. Health Place. 2009;15:1006-1013.

26. Hale L, Emanuele E, James S. Recent updates in the social and environmental determinants of sleep health. Curr Sleep Med Rep. 2015;1:212-217.

27. Desantis AS, Diez Roux AV, Moore K, Baron KG, Mujahid MS, Nieto FJ. Associations of neighborhood characteristics with sleep timing and quality: the multi-ethnic study of atherosclerosis. Sleep. 2013;36:1543-1551.

28. Fang SC, Subramanian SV, Piccolo R, et al. Geographic variations in sleep duration: a multilevel analysis from the Boston Area Community Health (BACH) Survey. J Epidemiol Community Health. 2015;69:63-69.

29. Troxel WM, Shih RA, Ewing B, Tucker JS, Nugroho A, D’Amico EJ. Examination of neighborhood disadvantage and sleep in a multi-ethnic cohort of adolescents. Health Place. 2017;45:39-45.

30. Pabayo R, Molnar BE, Street N, Kawachi I. The relationship between social fragmentation and sleep among adolescents living in Boston, Massachusetts. $J$ Public Health (Oxf). 2014;36:587-598.

31. National Center for Education Statistics. Combined user's manual for the ECLS-K eighth-grade and K-8 full sample data files and electronic codebooks. 2009; http://nces.ed.gov/pubsearch/pubsinfo.asp?pubid=2009004 Accessed June 15, 2019.

32. Beveridge AA, Catsambis S, Weber SR, Michalowski S, Ng C. Census data and geocoded location for the early childhood longitudinal study, kindergarten class of 199899 (ECLS-K) User's Guide, (NCES 2004 116). In: Education USDo, ed. Washington, D.C.: National Center for Education Statistics; 2004.

33. Kimbro RT, Denney JT. Neighborhood context and racial/ethnic differences in young children's obesity: structural barriers to interventions. Soc Sci Med. 2013;95:97-105.

34. Hicks AL, Handcock MS, Sastry N, Pebley AR. Sequential neighborhood effects: the effect of long-term exposure to concentrated disadvantage on children's reading and math test scores. Demography. 2018;55:1-31.

35. Theall KP, Scribner R, Broyles S, et al. Impact of small group size on neighbourhood influences in multilevel models. J Epidemiol Community Health. 2011;65:688-695.

36. Golley RK, Maher CA, Matricciani L, Olds TS. Sleep duration or bedtime? Exploring the association between sleep timing behaviour, diet and BMI in children and adolescents. Int J Obes (Lond). 2013;37:546-551.

37. Olds TS, Maher CA, Matricciani L. Sleep duration or bedtime? Exploring the relationship between sleep habits and weight status and activity patterns. Sleep. 2011;34:1299-1307. 
38. Osypuk TL, Diez Roux AV, Hadley C, Kandula NR. Are immigrant enclaves healthy places to live? The multi-ethnic study of atherosclerosis. Soc Sci Med. 2009;69:110- 120.

39. Robert SA, Reither EN. A multilevel analysis of race, community disadvantage, and body mass index among adults in the US. Soc Sci Med. 2004;59:2421-2434.

40. Stata Statistical Software: Release 14 [computer program]. College Station. TX: StataCorp LP; 2015.

41. Snijders T, Bosker R. Multilevel Analysis. London: Sage; 1999.

42. Lee $\mathrm{H}$. The role of local food availability in explaining obesity risk among young school-aged children. Soc Sci Med. 2012;74:1193-1203.

43. Stapleton LM, Kang Y. Design effects of multilevel estimates from national probability samples. Sociol Methods Res. 2016;47:430-457.

44. Cespedes EM, Hu FB, Redline S, et al. Chronic insufficient sleep and diet quality: contributors to childhood obesity. Obesity (Silver Spring). 2016;24:184-190.

45. Randler C, Faßl C, Kalb N. From Lark to Owl: developmental changes in morningness-eveningness from new-borns to early adulthood. Sci Rep. 2017;7:45874.

46. Plancoulaine S, Lioret S, Regnault N, Heude B, Charles M-A. The Eden Mother Child Cohort Study G. Gender-specific factors associated with shorter sleep duration at age 3 years. J Sleep Res. 2015;24:610-620.

47. Grandner MA, Williams NJ, Knutson KL, Roberts D, Jean-Louis G. Sleep disparity, race/ethnicity, and socioeconomic position. Sleep Med. 2016;18:7-18.

48. Hale L, Hill TD, Friedman E, et al. Perceived neighborhood quality, sleep quality, and health status: evidence from the Survey of the Health of Wisconsin. Soc Sci Med. 2013;79:16-22.

49. Fuller-Rowell TE, Curtis DS, El-Sheikh M, Chae DH, Boylan JM, Ryff CD. Racial disparities in sleep: the role of neighborhood disadvantage. Sleep Med. 2016;27-28:1-8.

50. Galland BC, Taylor BJ, Elder DE, Herbison P. Normal sleep patterns in infants and children: a systematic review of observational studies. Sleep Med Rev. 2012;16:213-222.

51. Guglielmo D, Gazmararian JA, Chung J, Rogers AE, Hale L. Racial/ethnic sleep disparities in US school-aged children and adolescents: a review of the literature. Sleep Health. 2018;4:68-80.

52. Owens JA, Jones C. Parental knowledge of health sleep in young children: results of a primary care clinic survey. Journal of Dev Behav Pediatr. 2011;32:447-453.

53. Slopen N, Lewis TT, Williams DR. Discrimination and sleep: a systematic review.Sleep Med. 2016;18:88-95.

54. Williams JA, Zimmerman FJ, Bell JF. Norms and trends of sleep time among US children and adolescents. JAMA Pediatr. 2013;167:55-6o. 
55. Matricciani L, Olds T, Petkov J. In search of lost sleep: secular trends in the sleep time of school-aged children and adolescents. Sleep Med Rev. 2012;16:203-211.

56. Sheehan CM, Frochen SE, Walsemann KM, Ailshire JA. Are U.S. adults reporting less sleep?: findings from sleep duration trends in the National Health Interview Survey, 2004 2017. Sleep. 2018;42:1-8.

57. Falbe J, Davison KK, Franckle RL, et al. Sleep duration, restfulness, and screens in the sleep environment. Pediatrics. 2015;135:e367-e375. 